\title{
Effects of multitasking and intention-behaviour consistency when facing yellow traffic light uncertainty
}

\author{
Daniel Wright ${ }^{1} \cdot$ Philippe A. Chouinard ${ }^{1}$
}

Published online: 3 June 2019

(C) The Psychonomic Society, Inc. 2019

\begin{abstract}
We examined the effects of multitasking on resolving response bistability to yellow traffic lights, using the performance metrics of reaction time and stopping frequency. We also examined whether people's actual behaviours, measured by implicit foot pedal responses, differed from their intentions related to these factors, as measured by explicit verbal commands. In a dual-task paradigm, participants responded to random traffic light changes, presented over a static background photograph of an intersection, using either foot pedals or verbal commands, while simultaneously identifying spoken words as either "animals" or "artefacts" via button pressing. The dual-task condition was found to prolong reaction times relative to a single-task condition. In addition, verbal commands were faster than the foot pedal responses, and conservativeness was the same for both types of responses. A second experiment, which provided a more dynamic simulation of the first experiment, confirmed that conservativeness did not differ between verbal commands and foot pedal responses. We conclude that multitasking affects a person's ability to resolve response bistability to yellow traffic lights. If one considers that prolonged reaction times reduce the amount of distance available to safely stop at intersections, this study underscores how multitasking poses a considerable safety risk for drivers approaching a yellow traffic light.
\end{abstract}

Keywords Driving $\cdot$ Intersections $\cdot$ Yellow traffic lights $\cdot$ Response bistability $\cdot$ Multitasking $\cdot$ Intention-behaviour consistency

There is widespread confusion about the expected response to a yellow traffic light (Jensen, 2011). This is exacerbated by the legal provision in many jurisdictions that permits a driver to cross a yellow traffic light if the driver does not have the distance available to safely stop (Marusek, 2014). Response bistability is defined as the simultaneous elicitation of two response associations (Wood, Chouinard, Major, \& Goodale, 2017). Unlike red and green lights that designate a single motor response (Templeton \& Franklin, 1992), yellow lights denote "stop" and "go" as two different possibilities, which compete to be executed into a motor action. Cisek and Kalaska (2005) shed some light as to how this might happen at a neurological level. Following the presentation of a visual stimulus specifying two competing actions, different sets of neurons in certain motor areas of the cortex fire to a visual stimulus, with only one set continuing to fire after an action is

Philippe A. Chouinard

p.chouinard@latrobe.edu.au

1 Department of Psychology and Counselling, School of Psychology and Public Health, La Trobe University, Melbourne, Victoria, Australia selected. At intersections, the presence of two possible responses to a yellow traffic light creates a dilemma zone. The dilemma zone is the time or distance range within the yellow light phase in which stopping or proceeding appear equally risky (Gugerty et al., 2014). A slow, reckless, or uncertain response by a driver encountering this dilemma can be disastrous. Rear-end collisions may occur if a driver stops too suddenly. On the other hand, a driver may collide with side traffic if the driver continues through the lights and has insufficient time to clear the intersection. Thus, it is crucial that drivers resolve this dilemma with a rapid and decisive response that is most appropriate for the situation.

The examination of a person's frequency of stopping responses when confronted with a yellow traffic light can provide insight into whether the individual has a tendency to make conservative or liberal decisions. Conservativeness is defined as a tendency to make the "stop" response, thereby minimising the probability of making a risky intersection crossing, whereas liberalness is the reverse. A conservative bias would be indicated by a comparatively higher threshold for accepting a "go" signal at a yellow traffic light, and a liberal bias is indicated by a lower threshold (Lynn \& Barrett, 2014; Stanislaw \& Todorov, 1999). Research suggests that response bistability increases the risks of 
both indecisive and reckless decisions. Elmitiny, Yan, Radwan, Russo, and Nashar (2010) demonstrated how increases in red traffic light violations transpire when yellow traffic light onsets occur within the dilemma zone: the distance at which equal numbers of drivers stop and go. Fewer red traffic light violations happen to drivers who are more conservative, with a tendency to stop when seeing a yellow traffic light. Consequently, a need exists to evaluate the contributing factors that increase conservativeness in normal drivers, which will in turn reduce red traffic light violations. In the present investigation, we examined the effects of multitasking and intention-behaviour consistency when facing yellow traffic light uncertainty. Next, we will discuss multitasking and intention-behaviour consistency.

Multitasking and intention-behaviour consistency are closely associated with two important driving performance metrics: reaction time (Brookhuis, Waard, \& Mulder, 1994) and conservativeness, as indexed by stopping frequencies. Namely, more conservative drivers stop more frequently under ambiguous situations. Multitasking is defined as the concurrent handling of more than one task (Salvucci \& Taatgen, 2008) using rapid reorientation between tasks ("task switching"; Rubinstein, Meyer, \& Evans, 2001). Intention-behaviour consistency describes the degree of difference between what individuals report intending to do in a driving situation, as indicated by their explicit responses, and their actual behaviour, as indicated by implicit responses. Intentions can be expressed as verbal responses (Nyberg et al., 2001).

There is overwhelming evidence that multitasking negatively impacts response speed. In particular, phone use while driving is problematic, due to its prevalence (Kidd, Tison, Chaudhary, McCartt, \& Casanova-Powell, 2016). A metaanalysis by Caird, Willness, Steel, and Scialfa (2008) showed that phone use triggered a mean reaction time increase of 250 ms. A further meta-analysis by Caird, Johnston, Willness, Asbridge, and Steel (2014) revealed that texting degraded performance even further, adding $260 \mathrm{~ms}$. Accordingly, mobile phone use is estimated to increase a driver's vehicle accident risk fourfold (Redelmeier \& Tibshirani, 1997). Multitasking may also affect the content of driver decisions. Increased errors and response variation are observed in many driving simulation studies (Hancock, Lesch, \& Simmons, 2003; Harbluk, Noy, Trbovich, \& Eizenman, 2007; Just, Keller, \& Cynkar, 2008). Notably, a naturalistic study by Strayer, Watson, and Drews (2011) observed that drivers using mobile phones were ten times more likely to fail to stop appropriately at a stop sign at a four-way intersection. However, a substantial gap in research still exists regarding the impact of multitasking on performance during intersection crossings. Specifically, it is unknown whether or not the response bistability produced from yellow traffic lights exacerbates performance decline beyond the previous mean estimates.

Multitasking can be operationalised using a dual task. A dual task is the addition of a secondary task while participants perform a primary task (Koch \& Tsuchiya, 2007). Dual-task interference is quantified by how much accuracy and reaction time are affected while participants perform two tasks, as compared to only one (Luck, 1998; Pashler, 1994). The central bottleneck theory (Welford, 1952) posits that only one task can be efficiently processed at a time by a central, amodal processing area (Dux, Ivanoff, Asplund, \& Marois, 2006). Performance on tasks higher in automaticity are typically expected to be less affected by a dual task (Logan, 1979), since they are theorised to exert fewer processing demands (Wickens \& McCarley, 2008). Problematically, different task modalities (i.e., vocal, manual, visual) may utilise parallel processing (Hazeltine, Ruthruff, \& Remington, 2006) and have mode-specific storage (Saults \& Cowan, 2007), potentially limiting interference. However, evidence points to some overlap in the selection processes for spoken and manual responses (Xue, Aron, \& Poldrack, 2008) and to bottlenecks when responding to auditory and visual stimuli (Harbluk et al., 2007). For this study, we had participants manually identify with button pressing an auditory presented stimulus as either an "animal" or "artefact," from dictated word lists by Rossion and Pourtois (2004), during a simulated driving task towards an intersection. This study was carried out to establish whether or not a secondary task would affect the manner in which participants respond to traffic lights.

The participants in our experiments responded to traffic lights using either foot pedals, which they had had many years of experience doing, or by verbal commands, which is not the typical way that drivers respond to traffic lights. The purpose of this manipulation was to examine intention-behaviour consistency - namely, is what we explicitly "say we do" the same as what we implicitly "actually do" while driving?

Research has established that motor responses and speech are valid representations of implicit and explicit processing, respectively (Goddard, Kahn, \& Adkins, 2015; Lupyan \& Ward, 2013; Schall, 2009). As the natural way of controlling a vehicle, foot responses are an intuitive representation of actual driver behaviour (Goddard et al., 2015). On the other side, verbalisation is thought to implicate a greater degree of higher-order cognitive processing (Schall, 2009) and is more likely to operate within conscious awareness (Lupyan \& Ward, 2013). Accordingly, verbal responses are found to lag motor responses by 150 to $300 \mathrm{~ms}$ (Castiello \& Jeannerod, 1991; Castiello, Paulignan, \& Jeannerod, 1991), well beyond the conservative $50 \mathrm{~ms}$ needed to neuromuscularly execute a vocalisation (Gracco \& Abbs, 1987). This does not mean that explicit responses are confined to reflecting declarative knowledge, but rather, they require additional computational power and can operate independently from those that are more implicit (see Stanley \& Krakauer, 2013, for an excellent discussion).

Research suggests that more explicit verbal responses will be more conservative. Explicit verbal commands are more 
cognitively penetrable (Evans, 2008; Wilson, Lindsey, \& Schooler, 2000)-where cognitive penetrability is defined as the degree to which thinking can influence a behaviour - and is more susceptible to modification by social expectations (Stokes, 2013). Careful driving is expected of drivers. As a result, drivers asked to self-report will tend to provide a desirable report (Lajunen, Corry, Summala, \& Hartley, 1997; Lajunen \& Summala, 2003). Since implicit foot pedal responses are less cognitively penetrable, we would expect riskier and more liberal responses with foot pedals than with verbal commands. In other words, participants will explicitly "say" how they are expected to act and will implicitly "do" as they would typically respond while driving.

With this in mind, we carried out two experiments to examine the effects of multitasking on resolving yellow traffic light response bistability and to evaluate whether people's actual behaviours, measured by implicit foot pedal responses, differed from their intentions, as measured by explicit verbal commands. Our first experiment (a static multitasking experiment) isolated and compared responses to changes in traffic lights over a static background, whereas our second experiment (a dynamic simulated intersection approach experiment) compared responses in a more realistic simulation of a traffic light approach. Including the second experiment served to establish ecological validity. The first experiment allowed us to examine multitasking and intention-behaviour consistency in a highly controlled manner with the use of static images. However, driving is a dynamic not a static process. Therefore, we reexamined some aspects of this experiment, specifically the intention-behaviour relationship, in a second experiment with a more more dynamic setting, to see whether our findings might converge in a more realistic simulation.

Our first hypothesis was that multitasking would slow reaction times and hamper conservative decision making, which are both important for accident prevention when people are confronted with a yellow traffic light specifying two possible actions. We also had a second hypothesis, whereby people's responses would be less conservative, more decisive, and less affected by dual-task interference when they responded implicitly with foot pedals than when they responded explicitly with verbal commands.

\section{Method}

\section{Experiment 1: Static multitasking experiment}

The experiment took approximately $30 \mathrm{~min}$ to complete.

Participants Thirty (19 males and 11 females; age range: 1857 years, mean $=28.3$ ) adults participated in Experiment 1 . All participants reported having at least three years of experience driving a motor vehicle. Two females were excluded from the analysis due to a recording failure of the foot pedals, and two males were excluded from the analysis due to insufficient quality of verbal recordings, leaving a total sample size of 26 participants (17 males and nine females; age range: 1857 years, mean $=27.7$ ). The participants were recruited from the La Trobe University community. Participants reported being right-handed and having normal or corrected-to-normal vision, which were the advertised inclusion criteria. Individuals were excluded from participation if they had a history of neurological or psychiatric disorders; were susceptible to epileptic seizures, migraines, or headaches; or required prescribed psychotropic medication or medication that could cause drowsiness. All participants provided informed written consent, and all procedures were approved by La Trobe University's human research ethics committee.

Driver background questionnaire This was a six-item self-report survey related to participants' driving history (Appendix 1). This survey was created to gain information about key factors identified from previous studies as influencing driving performance, such as years of driving experience (Langford, Methorst, \& Hakamies-Blomqvist, 2006), regular driving exposure (McGwin, Chapman, \& Owsley, 2000), vehicle accidents in the last six months (West, French, Kemp, \& Elander, 1993), recent "near misses" in the last six months (KornerBitensky, Kua, von Zweck, \& Van Benthem, 2009), and driving offences detected by police or camera in the last six months (Rothengatter, 1982). To maximise the response rate, the questions only required yes/no responses and were worded so as to avoid any perceived admission of guilt (Coutts \& Jann, 2011).

Apparatus The stimuli were presented on a Display++ LCD Monitor (Cambridge Research Systems) using E-Prime 2.0 (Psychology Software Tools Inc., 2012) and a Dell Precision 3610 desktop computer (Fig. 1). As is illustrated in Fig. 2, four traffic light photographs were used to simulate traffic light changes and elicit responses. Light colours and a fixation point to reduce eye movements (Legge \& Campbell, 1981) were added to an original image (provided courtesy of cardriving.com.au, website is no longer available) using Adobe Photoshop CC (Adobe Systems, 2015). The task involved a two-alternative forced choice (2AFC) task, in which participants were asked to give "go" or "stop" responses verbally or using foot pedals as the blank light randomly transitioned to either a green, yellow, or red light. Participants had a 3-s countdown before each task, and the light changed after $3 \mathrm{~s}$. A total of 25 trials were presented: Ten trials of red lights and ten trials of green lights were presented, in line with Pelli and Bex (2013) and Montag and Wilber (2003), and five trials of yellow light transitions were presented, to reflect their comparatively lower occurrence in real-life driving and to heighten response bistability by preserving their less frequent occurrence. Three types of responses were collected: foot pedal, verbal, and button 


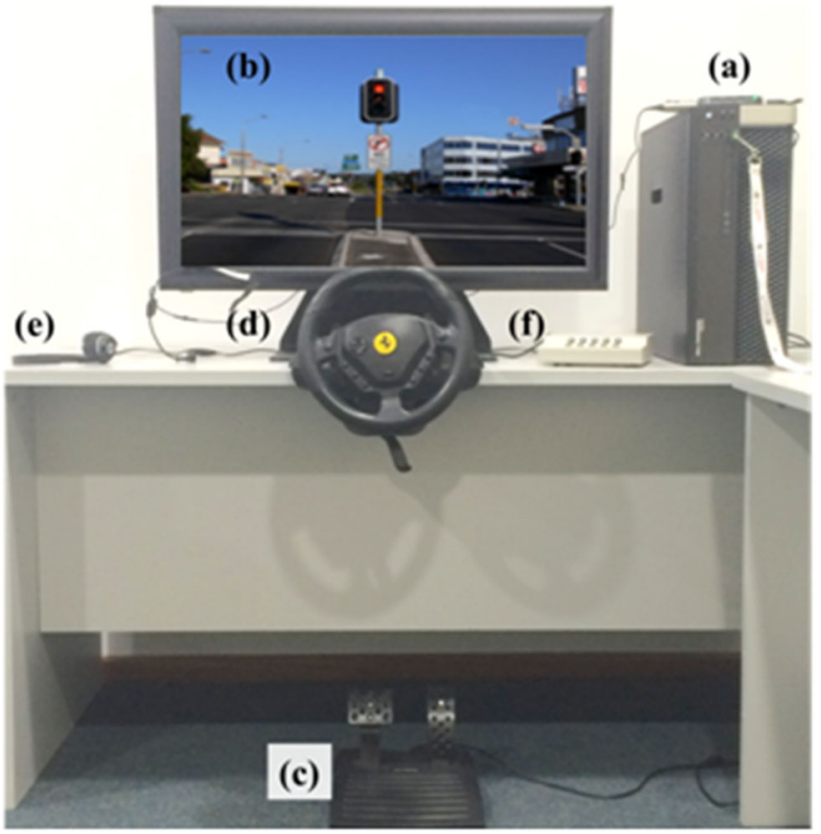

Fig. 1 Testing station. Stimuli were presented using (a) a Dell Precision 3610 desktop computer and (b) a Display++ LCD monitor (Cambridge Research Systems), chosen for its high, $120-\mathrm{Hz}$ refresh rate. Pedal responses were recorded with (c) a Thrustmaster ENZO Ferrari FFB steering wheel package, used in past driver behaviour studies (Bartlett et al., 2007; Vural et al., 2009). Verbal responses were recorded using (d) a Shure WH20XLR head-worn microphone, used in past studies to record for offline analysis. The dual-task stimuli were delivered via (e) over-ear Logitech headphones, with button responses recorded using (f) a Model 200a Serial Response Box (Psychology Software Tools Inc., 2012)

responses. Foot pedal responses were recorded with a Thrustmaster ENZO Ferrari FFB steering wheel package, used in past driver behaviour studies (Bartlett et al., 2007; Vural et al., 2009). E-Prime recorded online the reaction times and the types of responses (i.e., "accelerator" or "brake") made by the participant. Verbal responses were collected by E-Prime for $10 \mathrm{~s}$ at a sample rate of $44,000 \mathrm{~Hz}$ for offline analysis thorough a Shure WH20XLR head-worn microphone. The dual-task stimuli were delivered by E-Prime via Logitech headphones, and button responses were recorded online using E-Prime's Model 200a Serial Response Box (SRB; Psychology Software Tools Inc., 2012).

Animal-artefact identification task This identification task used items taken from the Rossion and Pourtois (2004) dataset (available at http://wiki.cnbc.cmu.edu/Objects), which are coloured versions of the original Snodgrass and Vanderwart (S\&V) objects (Snodgrass \& Vanderwart, 1980). We selected items from this dataset because the degree of familiarity in the general population for each item is published and wellestablished (Rossion \& Pourtois, 2004). Four lists of 13 artefacts and 12 animals were created (Appendix 2), with artefacts and animals paired according to familiarity scores - which is an important consideration given that familiarity can confound reaction time (Glass, Cox, \& LeVine, 1974). The mean familiarity scores were consistent between word lists. A oneway ANOVA confirmed that no significant differences in familiarity scores existed between the four word lists, $F(3,99)=$ $0.02, p=.996$ (see Appendix 3 for the means and standard deviations of each word list). All word list items were converted to audio, using the text-to-speech function in TextEdit (Apple Computers, 2014, Version 1.10). We also created audio recordings of these word lists, with the words played backward to create new sets of stimuli for the single-task condition. This reverse scrambling was done using in-house scripts written in Matlab (The MathWorks, Natick, MA, USA). Presenting incomprehensible stimuli during the single task controlled for the effects of the presence of sound (Ma, Hwang, \& Lin, 2009).

To increase accuracy and precision, E-Prime's Model 200a SRB was used to capture animal-artefact identifications via button pressing. A keyboard or mouse lacks reaction time precision, due to hardware quality (Plant, Hammond, \& Whitehouse, 2003), delays caused by operating systems (Plant \& Turner, 2009), and interferences arising from other hardware components (i.e., video card; Plant, Hammond, \& Turner, 2004). The SRB eliminates this variability by recording the reaction time before sending it to the computer. Struthers (2015) reported that the SRB exhibits a superior millisecond latency $(M=2.38, S D=0.70)$, as compared to either a keyboard $(M=15.02, S D=2.53)$ or a mouse $(M=$ 21.91, $S D=5.15)$, resulting in more accurate and precise measurements and fewer trials being required to achieve good sensitivity (Breakwell, 2006; Li, Liang, Kleiner, \& Lu, 2010).

Procedures Following completion of the demographic and driver background questionnaire, participants then proceeded to the main experiment. They each completed four conditions: (1) foot pedal responses with the single task, (2) foot pedal responses with the dual task, (3) verbal commands with the single task, and (4) verbal responses with the dual task. The order of the tasks was counterbalanced across participants using the Latin square method. This was done to prevent order effects. The sequence of events for any given trial was as follows: Participants were first presented with a blank traffic light. As can be seen in Fig. 2, a spoken word from an animalartefact word list was played through the headset during the transition of the blank traffic light to a random light colour (red, yellow, or green). Participants responded either verbally ("go" or "stop") or with the foot pedals ("accelerator" or "brake") using their right foot. This was done as either a single or a dual task. In the single-task condition, participants would perform this task while listening to the auditory recordings of the scrambled words. In the dual-task condition, participants would perform this task while listening to the intact auditory 


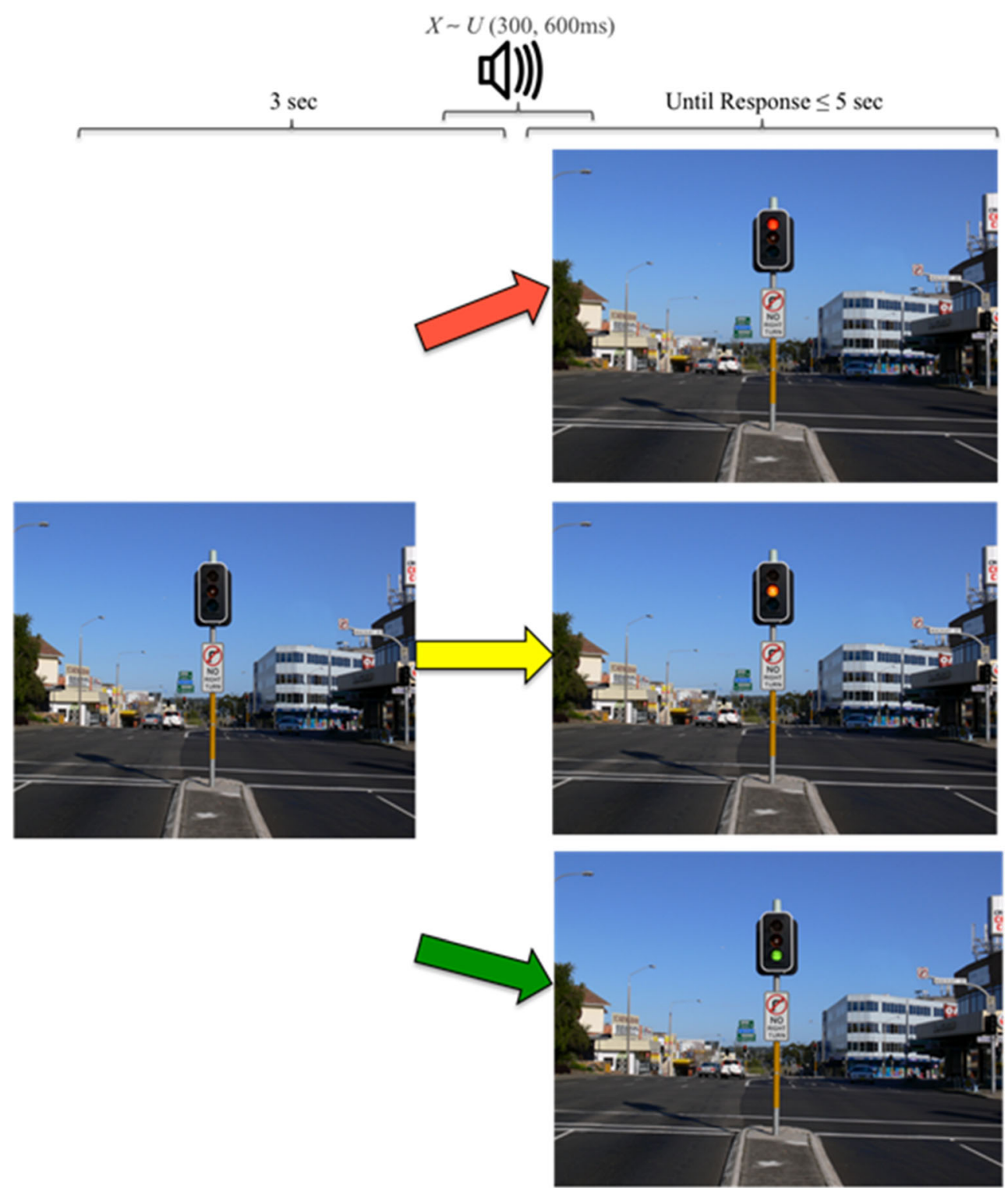

Fig. 2 Trial events. A trial began with the participant seeing the image of a blank traffic light to the left. The image was set to transition to randomly presenting one of the images to the right: the red light, yellow light, or green light. Slide transitions and audio stimuli from the dual task occurred simultaneously after $3 \mathrm{~s}$, with a varying stimulus onset time (jitter) of $300-600 \mathrm{~ms}$ to reduce predictability. Participants were required to respond verbally ("go" or "stop") or with foot pedals ("brake" or "accelerator") within $5 \mathrm{~s}$ recordings of animal and artefact words; they had to classify the words into their appropriate categories by pressing buttons on the SRB with their right hand (Button 1, "artefact"; Button 2 , "animal"). Each trial would end after both responses had been made or $5 \mathrm{~s}$ had passed, whichever was fastest. A 3-s break occurred between trials. Participants completed 25 trials per condition, and the order of trials was randomly generated by E-Prime. Participants were instructed to respond naturally to the traffic lights as they would when driving, and to return their foot to the floor after each trial was completed. Participants were instructed to respond to the traffic light first and then to make the animal-artefact identification. Although this interference task is uncommon while driving, it conceivably could tax people in ways similar to tasks that are sometimes, and should not be, performed while driving, such as pressing keys on a mobile phone in response to speech.

Statistical analyses Reaction times and the types of responses made by each participant were determined manually on a trialby-trial basis from the verbal recordings, using in-house scripts written in Matlab (The MathWorks, Natick, MA, USA). For each individual, the median reaction times for the foot pedal, verbal, and button responses were calculated for each condition, which is a measure that is less sensitive to 
outliers than the mean (Ratcliff, 1993). We decided to adopt this procedure instead of removing outliers to avoid "double dipping" (Motulsky, 2014) and because the typical $\pm 2 S D$ indicator can itself be affected by the outlying variables. The percentage of "stop" responses made by participants was also calculated for each of the different conditions. The averages and standard deviations for these different dependent variables are presented in the Results.

Given that our objective was to examine how different factors influence responses to yellow traffic lights, the rest of the statistical analyses were restricted to making comparisons between yellow traffic light conditions and how the overall performance in these conditions was related to driving history. Furthermore, as expected, there was little variability in stop frequencies for red and green traffic lights (see the Results), to allow for appropriate use of parametric statistics. Variance in the data is an assumption that must be met to allow for analysis of variance (ANOVA) and calculating Pearson correlation coefficients $(r)$. ANOVA was performed with task (single vs. dual) and response modality (foot pedals vs. verbal) as within-subjects factors. Separate ANOVAs were performed for the reaction times and the stopping frequencies as the dependent variable.

Finally, we determined the effects of age, frequency of driving, experience, driving offences, near misses, and accidents on reaction times and stopping frequencies during task performance, collapsed across the different yellow traffic light conditions. To this end, we calculated Pearson correlation coefficients $(r)$ that tested whether or not age, frequency of driving, and experience correlated with the overall reaction times and stopping frequencies across the yellow traffic light conditions. We also performed unpaired $t$ tests with Welch's corrections to account for unequal variances, to compare reaction times and stopping frequencies between participants with and without driving offences, near misses, and accidents in the last six months. Unless specified otherwise, the reported $p$ values were corrected for multiple comparisons, and statistical significance was evaluated in reference to the conventional alpha level of .05 for two-tailed tests.

\section{Experiment 2: Dynamic simulated intersection approach experiment}

The experiment took approximately an hour to complete. The participants in this experiment completed the same driver background questionnaire as in Experiment 1.

Participants Eight participants completed the experiment. As compared with Experiment 1, there was a larger proportion of male $(n=6)$ than female $(n=2)$ participants, and the average age was 3 years higher $(M=31.25$ years, $S D=12.06)$.
Apparatus The same apparatus used in Experiment 1 was also used in Experiment 2. As illustrated in Fig. 3, the stimuli were created using a single, 9-s video clip of an approach to an intersection. The approach was at $60 \mathrm{~km} / \mathrm{h}$, and no other traffic was on the road. Using the method of constant stimuli (Urban, 1910), we added ten yellow light onsets to the video clip that were estimated to encompass the dilemma zone. As shown in Appendix 4, the range of light changes was set between 1.3 to $4.5 \mathrm{~s}$, with eight equal intervals between. The static type 1 dilemma zone calculations of Zhang, Fu, and $\mathrm{Hu}$ (2014) were used as a reference point to ensure that the dilemma zone would be present in the intervals we used. This interval range was broadly consistent with other estimations of the dilemma zone (Bonneson, Middleton, \& Zimmerman, 2002; Elmitiny et al., 2010; Rakha, El-Shawarby, \& Setti, 2007). The yellow

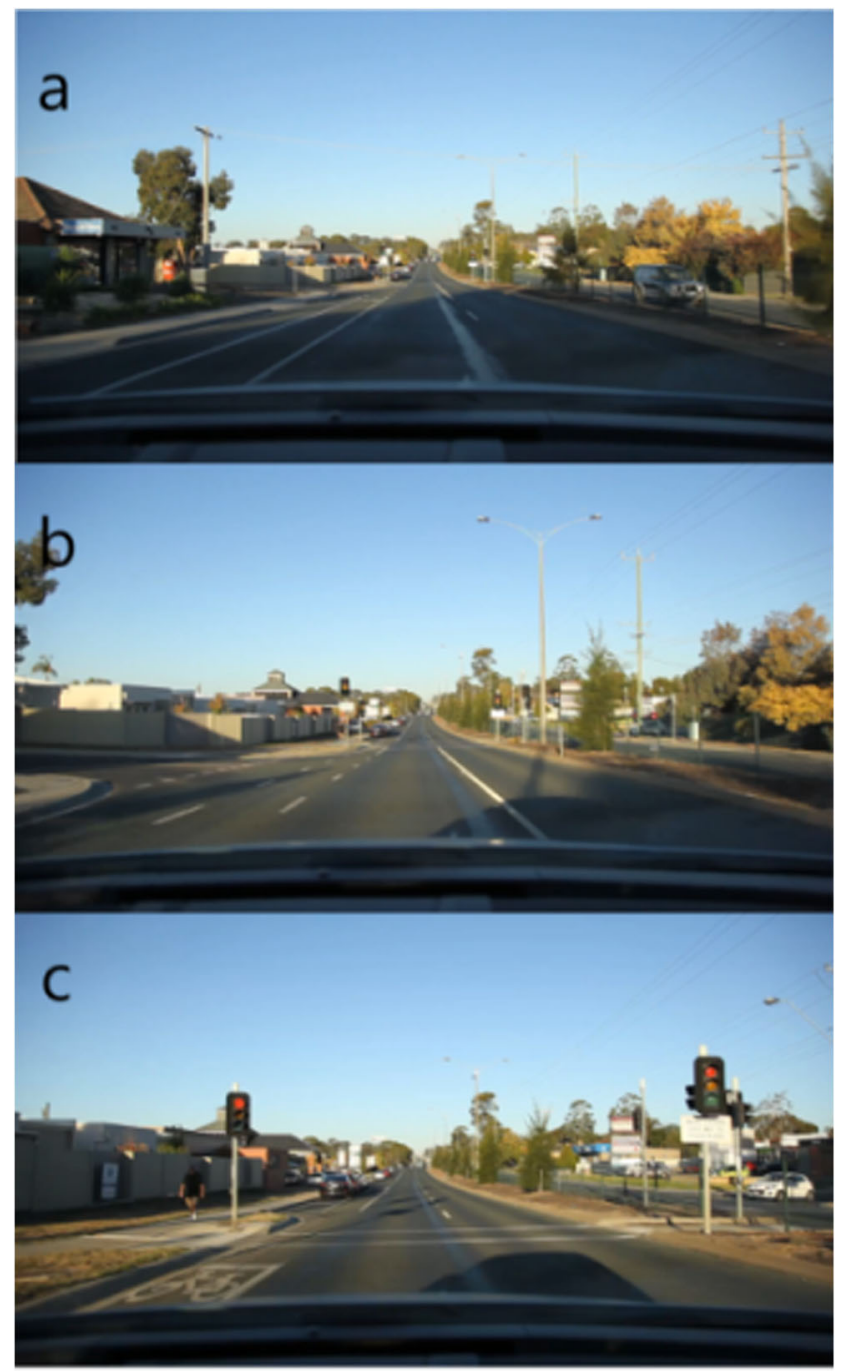

Fig. 3 Sequence of events for Experiment 2. In this trial, a yellow light change is scheduled to occur $3.08 \mathrm{~s}$ prior to the intersection crossing. a $3.0 \mathrm{~s}$ into the trial, when the traffic light is still green. b $5.0 \mathrm{~s}$ into the trial, when the light is yellow. c $7.0 \mathrm{~s}$ into the trial, when the light is red. Participants were required to respond verbally ("go" or "stop") or with foot pedals ("brake" or "accelerator") 
traffic light duration time was $4 \mathrm{~s}$, because this is the duration that Australia regulates for $60 \mathrm{~km} / \mathrm{h}$ zones (Levasseur \& Akcelik, 2014). An extra second was also added, to account for the mean perceptual reaction times found by Goh and Wong (2004). Intervals were rounded to one decimal place, to accommodate the 25 -fps frame rate used in the video. A video with no traffic light change was presented as catch trials.

Procedures Participants completed the simulated intersection approach task twice, using foot pedals ("brake" or "accelerator") and verbal commands (vocalising "go" or "stop"). Participants were instructed to respond naturally to the traffic lights, as they would when driving, and to return their foot to the floor after each trial was completed. Following the participant's response, the video terminated. Participants were shown each of the 11 videos ten times during each of the two conditions, with 220 clips presented in total. To control for any carryover effects, half the sample completed the verbal command condition first, and the other half completed the foot pedal condition first. The order of the trials was randomly generated by E-Prime.

Statistical analyses For each participant, we created a psychophysical curve for each type of response: verbal commands and foot pedal responses. The number of "stop" responses made by participants was recorded for each of the ten conditions (excluding the catch trials). For each participant, the frequency of "stop" decisions was converted into a probability $(P)$ of stopping for each light colour, represented as a digit between 0 and 1 . Yellow light responses had a probability between consistent "stop" responses at red lights and consistent "go" responses at green lights. Therefore, it was possible to convert the green, yellow, and red light responses into psychophysical curves using the following logistic function:

$P(x)=\left(\frac{e^{b_{0}+b_{1} x}}{1+e^{b_{0}+b_{1} x}}\right)$,

where $b_{0}$ and $b_{1}$ are coefficient estimates based on an initial general linear model (binary logit) fit. From this function, the point of subjective equality (PSE) was calculated as $P=.5$, with a lower PSE value signifying that a participant chose "stop" responses more frequently. This was taken to represent conservativeness of decision making, since a conservative decision maker was theorised to stop more frequently when confronted with a yellow light. Additionally, we calculated the bistability width $(\omega)$ as

$\omega=P .75-P .25$,

where $P_{.25}$ and $P_{.75}$ correspond to the logistic function results for $P=.25$ and $P=.75$, respectively. In this case, the bistability width $(\omega)$ provides a measure of variability in decision making, with higher $\omega$ values signifying greater uncertainty by the participant. We took this to represent decisiveness, since a decisive decision maker was theorised to show less uncertainty. These PSE and $\omega$ values were entered in pairedsamples $t$ tests as the dependent variables.

\section{Results}

\section{Driver background questionnaire}

According to the questionnaire, the number years that the participants reported driving a motor vehicle ranged between 3 and 37 years $(M=11.38, S D=9.08)$. The participants also reported driving between 0 and $30 \mathrm{~h}$ per week $(M=9.69, S D=7.17)$. In the six months preceding study participation, moderate numbers of participants reported a driving offence (yes, 7 ; no, 19) or a near miss (yes, 8; no, 18). A smaller proportion reported being in an accident (yes, 4; no, 22).

\section{Reaction times to the yellow traffic lights in the dual task}

Descriptive statistics across all conditions, including the red and green traffic light conditions, are presented in Tables 1 and 2. Given that our objective was to examine how various factors might influence response bistability to yellow traffic lights, the Results will focus on statistical comparisons between the yellow traffic light conditions and how performance in these conditions might correlate with driving history.

As expected, participants were slower to respond to the yellow traffic lights under dual- than single-task conditions [main effect of task: $F(1,25)=11.38, p=.002, \eta^{2}=.313$; Fig. 4a]. Contrary to our expectations, participants were slower to respond to the yellow traffic lights when they responded with the foot pedals, as they would when driving, than when they verbalised "go" or "stop," which are not conventional responses [main effect of response modality: $F(1$, $25)=39.00, p<.001, \eta^{2}=.609 ;$ Fig. 4a]. No interaction between task and response modality was observed $[F(1,25)$ $=0.12, p<.733, \eta^{2}=.005$; Fig. 4a]. Correlation analyses revealed that reaction times to the yellow traffic lights correlated positively with both age $[r(24)=.58, p=.002$, Fig. 4 b $]$ and experience $[r(24)=.43, p=.027$, Fig. $4 \mathrm{c}]$, but not with frequency $[r(24)=.28, p=.168]$. Reaction times did not differ between participants with and without driving offences $[t(20)$ $=1.33, p=.198, d=0.32]$, near misses $[t(7)=0.59, p=.574, d$ $=0.21]$, or accidents $[t(3)=0.15, p=.891, d=0.11]$ in the last six months. 
Table 1 Descriptive statistics for driving performance in Experiment 1

\begin{tabular}{|c|c|c|c|c|}
\hline Condition & $\begin{array}{l}\text { Average reaction } \\
\text { time (ms) }\end{array}$ & $\begin{array}{l}\text { Standard deviation } \\
\text { reaction time (ms) }\end{array}$ & $\begin{array}{l}\text { Average stop } \\
\text { frequency }(\%)\end{array}$ & $\begin{array}{l}\text { Standard deviation } \\
\text { stop frequency }(\%)\end{array}$ \\
\hline \multicolumn{5}{|c|}{ Single task, verbal response } \\
\hline Green light & 498.30 & 86.96 & 0.00 & 0.00 \\
\hline Red light & 520.70 & 96.51 & 99.62 & 1.96 \\
\hline Yellow light & 499.03 & 88.77 & 82.31 & 36.80 \\
\hline \multicolumn{5}{|c|}{ Single task, foot response } \\
\hline Green light & 502.75 & 96.21 & 2.69 & 7.24 \\
\hline Red light & 562.79 & 79.79 & 93.46 & 12.31 \\
\hline Yellow light & 593.46 & 86.82 & 79.23 & 34.17 \\
\hline \multicolumn{5}{|c|}{ Dual task, verbal response } \\
\hline Green light & 694.63 & 157.84 & 3.46 & 6.29 \\
\hline Red light & 692.82 & 148.34 & 97.69 & 6.52 \\
\hline Yellow light & 674.90 & 136.19 & 85.38 & 29.15 \\
\hline \multicolumn{5}{|c|}{ Dual task, foot response } \\
\hline Green light & 695.87 & 193.17 & 6.92 & 10.87 \\
\hline Red light & 688.35 & 176.83 & 91.54 & 11.56 \\
\hline Yellow light & 756.33 & 246.41 & 82.31 & 30.11 \\
\hline
\end{tabular}

\section{Stopping frequencies to the yellow traffic lights for the dual task}

Stopping frequencies to the yellow traffic lights did not differ between the dual- and single-task conditions $[F(1$, $25)=0.77, p=.387, \eta^{2}=.030$; Fig. 4d], nor did they differ when participants responded with the foot pedals versus by saying "go" and "stop" $[F(1,25)=1.19, p=$ $.285, \eta^{2}=.005$; Fig. 4d]. No interaction between task and response modality was observed $[F(1,25)=39.00, p$ $=1.000, \eta^{2}=.609$; Fig. 4d]. Correlation analyses revealed that stopping frequencies to the yellow traffic lights did not correlate with age $[r(24)=-.24, p=$ $.236]$, experience $[r(24)=-.35, p=.080]$, or frequency $[r(24)=.09, p=.653]$. Stopping frequencies to the yellow traffic lights also did not differ between participants with and without driving offences $[t(8)=0.39, p=$ .707, $d=0.17]$, near misses $[t(9)=0.78, p=.455, d=$ $0.25]$, or accidents $[t(3)=1.31, p=.273, d=0.31]$ in the last six months.

\section{Classification reaction time during the dual task}

During the dual task, participants were as fast in classifying objects with button pressing when they responded to the yellow traffic lights verbally as when they responded with the foot pedals $[t(25)=0.35, p=$ $.732, d=0.16$; Fig. 5a]. Correlation analyses revealed that reaction times to the yellow traffic lights correlated positively with both age $[r(24)=.41, p=.036$; Fig. 5b]

Table 2 Descriptive statistics for classification performance in Experiment 1

\begin{tabular}{|c|c|c|c|c|}
\hline Condition & $\begin{array}{l}\text { Average reaction } \\
\text { time }(\mathrm{ms})\end{array}$ & $\begin{array}{l}\text { Standard deviation } \\
\text { reaction time }(\mathrm{ms})\end{array}$ & $\begin{array}{l}\text { Average } \\
\text { accuracy }(\%)\end{array}$ & $\begin{array}{l}\text { Standard deviation } \\
\text { accuracy }(\%)\end{array}$ \\
\hline \multicolumn{5}{|c|}{ Dual task, verbal response } \\
\hline Green light & $1,264.49$ & 276.63 & 96.54 & 6.29 \\
\hline Red light & $1,226.25$ & 239.27 & 91.54 & 11.56 \\
\hline Yellow light & $1,294.55$ & 292.28 & 95.38 & 10.29 \\
\hline \multicolumn{5}{|c|}{ Dual task, foot response } \\
\hline Green light & $1,325.41$ & 312.85 & 88.41 & 11.14 \\
\hline Red light & $1,271.95$ & 321.94 & 90.09 & 12.16 \\
\hline Yellow light & $1,317.22$ & 343.76 & 85.58 & 17.57 \\
\hline
\end{tabular}




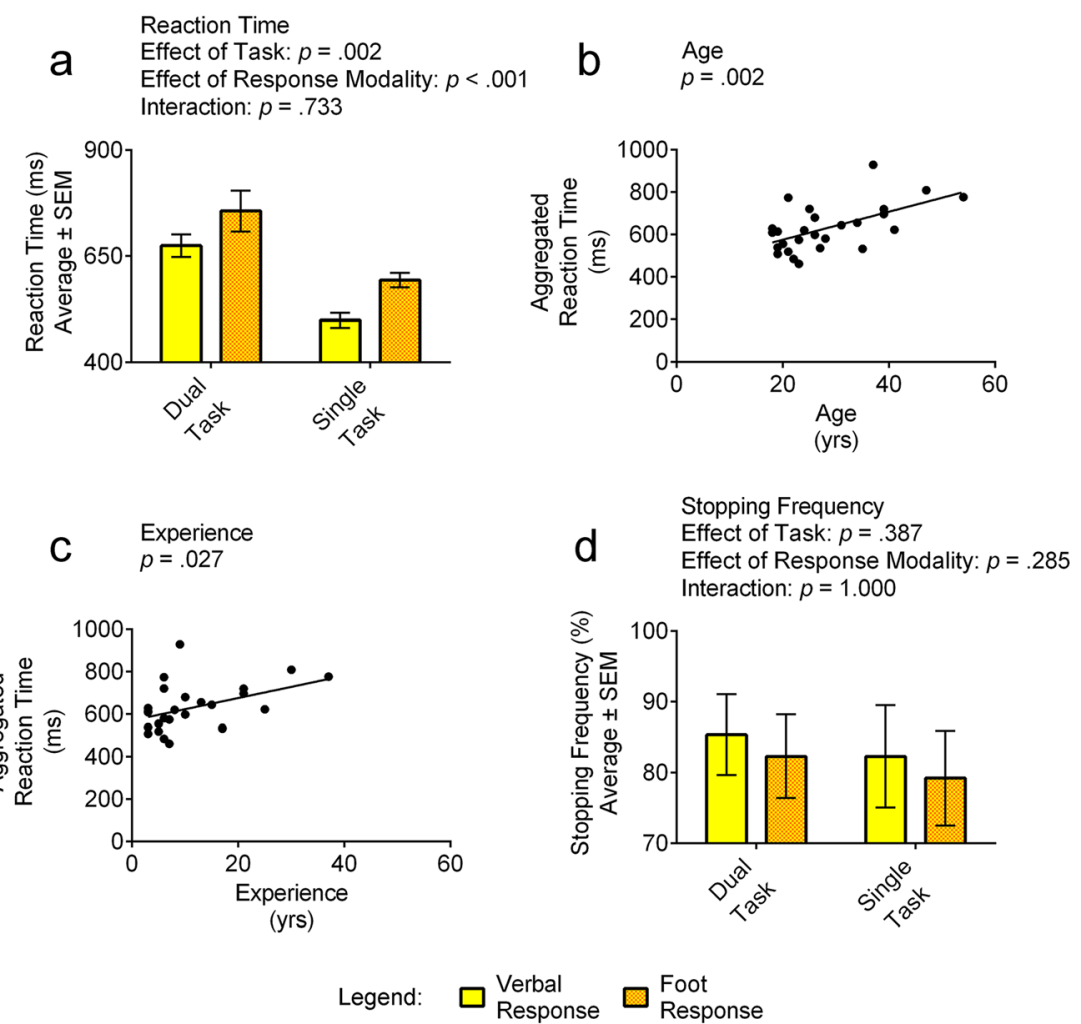

Fig. 4 Driving performance during the yellow traffic light conditions in Experiment 1 . The figure provides a summary of the main findings with regard to the effects of the dual task on driving performance. a Average reaction times during the dual- and single-task conditions, when participants gave their responses either verbally or with the foot pedals, as they

normally would while driving. Main effects of task and response modality were observed. b, c Linear correlations of the aggregated reaction times, increasing as a function of both age (b) and experience (c). d How frequently participants stopped. Error bars represent SEMs

and experience $[r(24)=.45, p=.022$; Fig. $5 \mathrm{c}]$, but not with frequency $[r(24)=-.06, p=.787]$. Reaction times did not differ between participants with and without driving offences $[t(12)=0.54, p=.599, d=0.20]$, near misses $[t(11)=0.34, p=.741, d=0.16]$, or accidents $[t(4)=0.70, p=.521, d=0.23]$ in the last six months.

\section{Classification accuracy during the dual task}

During the dual task, participants were more accurate in classifying objects with button pressing while they responded to the yellow traffic lights verbally, as compared to when they used the foot pedals $[t(25)=2.98, p$ $<.001, d=0.48$; Fig. 5d]. Performance in classifying objects was almost $10 \%$ worse with the foot pedals. Correlation analyses revealed that classification accuracy did not correlate with age $[r(24)=.25, p=.225]$, experience $[r(24)=-.35, p=.084]$, or frequency $[r(24)=$ $.32, p=.111]$. Classification accuracy also did not differ between participants with and without driving offences $[t(11)=0.24, p=.813, d=0.14]$, near misses $[t(18)=$ $0.66, p=.517, d=0.23]$, or accidents $[t(6)=0.12, p=$ $.911, d=0.10]$ in the last six months.

\section{Experiment 2: Dynamic simulated intersection approach experiment}

\section{Background driver questionnaire}

The participants completing Experiment 2 had, on average, three more years of driving experience than those in Experiment 1 ( $M$ $=14.50$ years, $S D=11.95)$, but they drove for a similar number of hours per week $(M=8.25 \mathrm{~h}, S D=9.47)$.

\section{Index of conservativeness and decisiveness for the simulated intersection}

The analysis of PSE and $\omega$ values did not detect significant differences between the foot pedal and verbal responses, and did not support the hypothesis that people make more conservative responses while responding explicitly than while responding implicitly. Namely, the difference between the PSEs of foot pedal $(M=1.86, S D=0.21)$ and verbal $(M=$ $1.84, S D=0.22)$ responses was not statistically significant, $t(7)=0.26, p=.799, d=0.09$. Likewise, the difference between the $\omega$ values of foot pedal $(M=0.57, S D=0.52)$ and verbal $(M=0.54, S D=0.42)$ responses was also not statistically significant, $t(7)=0.50, p=.632, d=0.18$. 
a

Reaction Time on Classification Task $p=.732$

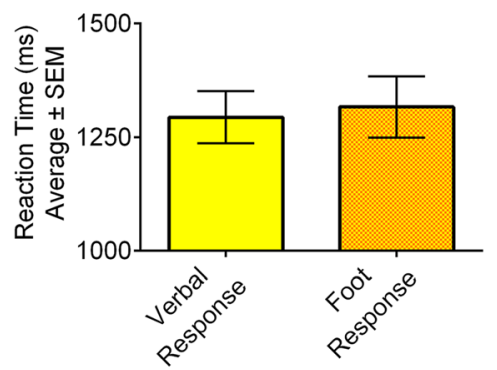

C Experience

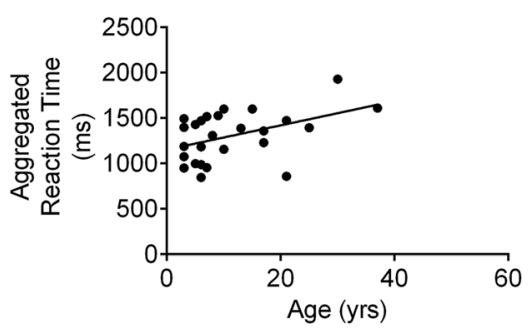

Fig. 5 Classification performance during the yellow traffic light conditions in Experiment 1. The figure provides a summary of the main findings with regard to performance on the object classification task. a Average reaction times in providing manual button responses while participants also responded to yellow traffic lights, either verbally or with the foot pedals.(b, $\mathbf{c}$ Linear correlations of the aggregated reaction

\section{Discussion}

Experiment 1 assessed the effects of multitasking on yellow traffic light responses and tested whether or not a discrepancy existed between intentions and behaviour, whereas Experiment 2 explored further whether people differed in the relative conservativeness of their responses when making implicit or explicit responses in a more dynamic situation. The second experiment differed from the first in two ways: (1) There was no multitasking, and (2) we attempted to study conservativeness in a more realistic setting.

We hypothesised that multitasking would hamper fast and conservative decision making for both foot pedal and verbal responses, and that foot responses would be more implicit and less disrupted than the verbal responses. We also hypothesised that explicit responses would be more conservative than implicit responses. The first hypothesis was partially supported. Multitasking prolonged reaction times across response modalities. Our second hypothesis was not supported. No differences were observed in the degree of conservativeness in the responses made between the foot pedal and verbal commands in both experiments. The convergence in results between our experiments affirms a degree of ecological validity to Experiment 1, which was arguably less realistic than b Age

$p=.036$

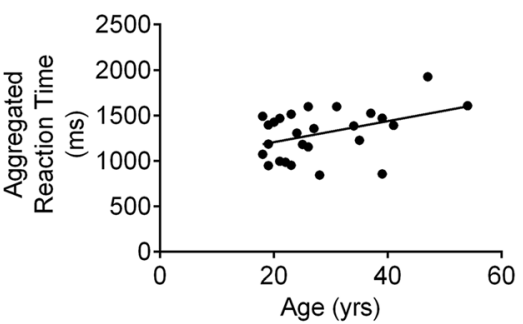
d $\begin{aligned} & \text { Accuracy on Classification Task } \\ & p<.001\end{aligned}$

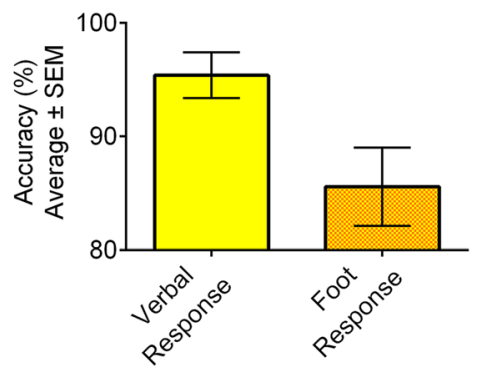

times, increasing as a function of both age (b) and experience (c). d How accurate participants were at the object classification task while also responding to the yellow traffic lights, either verbally or with the foot pedals. Participants were significantly worse in the latter than the former condition. Error bars represent SEMs

Experiment 2. It is unlikely that the convergence between the experiments arose from a lack of power. The effect sizes reported for conservativeness between foot and verbal responses were miniscule in both cases (Exp. 1, $\eta^{2}=.005$; Exp. 2, $d=0.09$ ) and would not be detected with reasonable sample sizes. Finally, the foot responses were not less disrupted than the verbal responses in the dual task in Experiment 1. Contrary to our expectations, the foot responses were slower than the verbal responses in the dual task.

In the ensuing discussion, we expand on four key findings: (1) the slower responses to yellow traffic lights while multitasking, (2) the faster verbal commands than foot responses, (3) the lack of effects of response modality on conservativeness, and (4) the age effects observed on reaction times and stopping frequencies. We end our article by discussing the implications of these key findings for future technological applications.

\section{Key finding 1: Responses to yellow traffic lights are disproportionately slower while multitasking}

Our results complement a large body of evidence cataloguing the deleterious effect of multitasking while driving (Caird et al., 2014; Caird et al., 2008). This was evident in the slower 
reaction times during the dual-task conditions (Fig. 4a, Table 1). Reaction time increases caused by distracted driving have substantial practical implications. For example, Carney, McGehee, Harland, Weiss, and Raby (2015) reviewed dashboard cameras from 1,691 crashes of drivers aged between 16 and 19, and determined that distraction was implicated in $60 \%$ of the crashes, tremendously exceeding government estimates. Their analysis also revealed slower reaction times when emergency braking was implicated in a considerable proportion of rear-end collisions. Although increases in reaction times cannot be asserted to have caused the collisions, they certainly added to the probability of a collision occurring. Had those drivers not been distracted and had additional time and distance to brake, it is conceivable that many of these collisions could have been avoided.

In our study, participants classified, by button pressing, auditorily presented words for animals and manmade artefacts. Although this is not something one typically does while driving, our results revealed that the manipulation was successful in creating interference. Auditory tasks are commonly used to approximate mobile phone use (Harbluk et al., 2007). However, given that such approximations are typically conservative (Caird et al., 2008), the observed effects are likely not inflated. Rather, the true effects of multitasking are probably greater, because drivers commonly engage in substantively more complex multitasking than the dual task performed by the participants in this study. For example, drivers self-report using GPS devices (Lee, Forlizzi, Hudson, \& Jun, 2014), eating (Irwin, Monement, \& Desbrow, 2014), and even reading a newspaper (AA Insurance, 2014), as well as changing clothes (Hurwitz et al., 2016) while driving. These real-life multitasking activities are concerning when one considers that only comparatively minor amounts of additional cognitive load are required to significantly increase reaction times, as demonstrated by our study. In many jurisdictions, legislation prohibits drivers from using electronic devices, primarily focusing on drivers making physical contact with the device (Victorian Government, 2009). Consequently, in these jurisdictions, there is a distinction between illegal "hands-on" use of devices and legal "hands-free" devices (i.e., Bluetooth car phone systems). However, rather than simply campaigning against "eyes off the road" (Australian Mobile Telecommunications Association, 2015), the cognitive impairment caused by multitasking should be equally considered, given that it is similarly debilitating (Strayer, Drews, \& Crouch, 2006).

\section{Key finding 2: Verbal commands are faster than foot pedal responses}

The implicitness of foot responses was posited to produce greater speed, due to their conceivable automaticity (Shine
\& Shine, 2014). Research is clear that increasing task automaticity by mass practice leads to faster reaction times (Scheel, 2010; Schneider \& Chein, 2003; Schumacher et al., 2001). However, foot pedal responses were found to be slower than verbal responses while making yellow traffic light responses (Fig. 4a, Table 1). A contributing factor may have been the travelling difference between the starting position and the foot pedal; however, this is also necessary for effective braking. It may also be the case that performing a routine response may decrease vigilance or encourage mind-wandering, which can hamper the initiation of efficient, automatic systems and increase reaction times (Cerezuela, Tejero, Chóliz, Chisvert, \& Monteagudo, 2004; Chapman, Ismail, \& Underwood, 1999; Lajunen et al., 1997; Sullman \& Taylor, 2010). Reaction time differences were greatest between foot pedal and verbal responses when responding to yellow traffic lights (Table 1). Given that responding to a yellow traffic light appropriately requires a certain degree of attention and cognitive supervision (Blaser \& Shepard, 2009), both of which depend on vigilance, a driver operating on "autopilot" is more likely to react more slowly, and perhaps more inappropriately, than one driving more carefully.

Inattentive states have consistently been shown to be suboptimal as compared with focused attention (i.e., "alertness" and "vigilance") on measures of both reaction times and accuracy (Campagne, Pebayle, \& Muzet, 2004; Lisper, Laurell, \& Van Loon, 1986). This is because attention is able to decrease external noise ( $\mathrm{Lu} \&$ Dosher, 1998) and so reduce the attended objects' signal intensity (Carrasco, Penpeci-Talgar, \& Eckstein, 2000; Yeshurun \& Carrasco, 1999). Beyond this, attention is argued to accelerate the rate of information processing (Carrasco \& McElree, 2001). Conversely, inattention diminishes the driver's ability to notice critical changes in the road environment at intersections (Caird, Edwards, Creaser, \& Horrey, 2005; Knowles \& Tay, 2002). The practical implications of slower foot responses are concerning, because people actually use their feet as opposed to making verbal commands when controlling vehicles in the real world. Thus, our findings raise questions about whether or not a more cognitively supervised modality, such as voice control, might be safer for controlling vehicles.

Across all light conditions (yellow, red, and green), the foot pedal responses recorded in our study demonstrated more variability in reaction times than the verbal responses (see the standard deviations reported in Table 1). We offer two explanations. First, the greater spread in reaction times for the foot pedal responses may reflect different levels of driving experience across participants. It is conceivable that there would be less variability in more experienced drivers. Conversely, given that people do not typically operate vehicles using 
their voice, one would expect similar variability across different levels of driving experience. Second, participants could have chosen to be more decisive when making verbal responses. It is conceivable that explicit responses are more likely to reflect a conscious rule and to be less influenced by other ongoing mental operations that are more implicit responses. However, fast, heuristic-driven responses can come at the cost of reduced flexibility in decision making and the risk of prematurely "seizing" or "fixating" on incorrect answers (Kruglanski \& Webster, 1996; Smith, 1995). Loss of flexibility can lead to dangerous adaptive strategies (Etienne, Marin-Lamellet, \& Laurent, 2013). The converse of this trade-off may be evident in the classification task. Unlike with traffic light responses, there were no differences between verbal and button press reaction times (Table 2, Fig. 5a). However, verbal classifications were significantly more accurate than button presses (Fig. 5d). Flexibility is crucial to real-world driving scenarios, because such scenarios are unique and potentially subject to rapid changes (A. C. Stein \& Dubinsky, 2011), and the driver needs to strike an optimal balance of speed and accuracy. Further research will be needed to establish and quantify the presence of the speedaccuracy compromise in yellow traffic light decisions, to ascertain the conditions under which drivers might resort to inflexible and rigid decision-making in a complex and changeable road situation.

\section{Key finding 3: Response modality did not impact conservativeness}

What people said they would do while driving was found to be the same as what they actually did. No difference was found between stopping frequencies between foot pedal and verbal responses (Fig. 4a). However, a limitation was that possible social influences that might have motivated liberal responses were not taken into account. Although social influence was initially hypothesised to create conservative decisions, it might be that, for some participants, social influence promoted liberal decision making (i.e., they were more likely to go rather than stop at a yellow traffic light). The most applicable self-serving motivation is the motivation to finish the task quickly. In real-life driving situations, reckless decisions occur as drivers compete for space as a function of time. Driver self-report studies have demonstrated that violations are often incurred when trying to get somewhere in a hurry (Gras et al., 2006; Hatfield \& Job, 2006). Further self-serving motivations that can inspire liberal decision-making include the desire to raise social status through risk-taking (Møller \& Gregersen, 2008), to manage a sense of threat (Taubman Ben-Ari, Florian, \& Mikulincer, 2000), and to alleviate frustration (Shamoa-Nir \& Koslowsky, 2010). Further research might benefit from attempts to capture these motivations using predictors of reckless driving, such as the Driver Behaviour Questionnaire (Wishart, Freeman, \& Davey, 2006).

Another consideration is that implicit foot pedal responses might have been more cognitively penetrable than we had initially predicted, and so influenced by pro-social motivations (Ferguson \& Bargh, 2004; Perugini, Conner, \& O'Gorman, 2011; van Baaren, Holland, Kawakami, \& van Knippenberg, 2004). A study that ingeniously combined both of these ideas was Valdesolo and DeSteno (2008), which revealed that explicit hypocritical judgments about other participants' behaviour were eliminated under a dual task. This suggested that explicit self-serving judgments were overridden by implicit pro-social attitudes. Taken collectively, both explicit and implicit responses were consistent in their conservativeness. However, more sensitive measures should be used to test whether divergent motivations underpin these response types.

\section{Key finding 4: Middle aged and more experienced drivers are slower and less likely to stop}

Our results revealed that more experienced drivers and older drivers tended to be slower. Reaction times increased as a function of both experience (Fig. 4c) and age (Fig. 4b). In opposition to this finding, earlier research suggested that more experienced drivers will perform faster when making implicit decisions and when facing uncertainty. In tandem with this, middle-aged drivers tend to be more experienced, and so are commonly considered safer. This is because experience is tied to automaticity. More experienced drivers have a lower crash risk (Bureau of Infrastructure Transport and Regional Economics, 2013) and exhibit greater task automaticity, evidenced by faster reaction times and better performance under dual-task conditions (Sagberg \& Bjornskau, 2006). On the other hand, recently licensed drivers, who are in the process of automatising driving tasks, have the highest crash risk (McCartt, Shabanova, \& Leaf, 2003). Nevertheless, more experienced drivers were found to be slower and not to be more conservative than less experienced drivers.

We offer two explanations for the slower reaction times in middle-aged and more experienced drivers. First, experienced drivers may have been more 
susceptible to inattention, due to the routine nature of our paradigm. As we explained earlier, the more routine a task is, the less vigilant one becomes, which diminishes attention. Responding to a traffic light is more routine for a more experienced driver than it is for a less experienced driver. Second, the effects of age could have contributed to slower reaction times in the more experienced drivers, given that processing speed and visual-processing abilities decline with age (Owsley et al., 1998; Stutts, Stewart, \& Martell, 1998). Furthermore, middle-aged drivers may avoid driving in conditions in which they feel uncomfortable (Ball et al., 1998) and not overestimate their abilities (Marottoli \& Richardson, 1998), reducing their exposure to the challenging driving conditions that are needed to facilitate learning and growth. This is in opposition to the tendencies of younger drivers to overestimate their driving ability (Groeger \& Brown, 1989) and to exhibit impulsive, risky, and thrill-seeking behaviour (Steinberg, 2007). Further research will be needed to develop strategies to mitigate declines in processing speed in middleaged drivers and to protect experienced drivers against the effects of inattention blindness.

\section{Implications for technological applications}

Our findings are informative for the implementation of new technologies that are currently being used to improve driver safety. Three relevant technological developments that are relevant to yellow traffic light responses are intersection collision warning systems (ICWSs), the signal timing of traffic lights, and voice control car systems.

ICWSs provide in-car warnings to drivers, alerting them to an imminent intersection collision (Belz, Robinson, \& Casali, 1999; Chang, Lin, Hsu, Fung, \& Hwang, 2009; Chen, Cao, \& Logan, 2011), which has the potential to reduce right angle, or "T-bone", collisions. These systems are currently in development and have yet to be integrated into mass-market vehicle manufacturing. ICWS warning systems commonly use auditory warnings as a means of reducing visual load (Yan, Xue, Ma, \& Xu, 2014). However, our study showed that the addition of meaningful, single-word auditory stimuli significantly prolonged reaction times (Fig. 4a). In an imminent collision situation, the additional auditory stimuli might prolong reaction times if the driver has already seen the hazard. Further research is suggested to assess whether or not ICWS increases reaction times and whether or not it is effective while drivers are multitasking.
The study lends further support for the use of dynamic yellow traffic light phase times. Traffic lights in many countries use algorithms that extend the yellow traffic light phase for times of day when traffic is heavy or there is inclement weather. Yellow traffic light phase times are hugely important because time may be a driver's single greatest resource when crossing an intersection. Standardised phase times are problematic because drivers regularly exceed the speed limits at intersections (David, 2015) and because of the panoply of individual and situational factors that potentially exacerbate response bistability (Zhang et al., 2014). Dynamic equations, on the other hand, change the phase time based on the anticipated presence of risk factors, such as environmental factors that reduce drivers' ability to perceive the lights and decelerate, as well as anticipated approach speeds (McGee et al., 2012). Our study showed significant reaction time differences when responding to traffic lights when drivers were multitasking (Table 1, Fig. 4a) and when they were older (Fig. 4b) and more experienced (Fig. 4c). These differences might mean that the standardised time is insufficient at particular intersections for some drivers. If the time is insufficient, the dilemma zone expands, leading more drivers to emergency brake or make risky crossings (H. S. Stein, 1986). For this reason, trends in the United States, Canada, and Germany are toward dynamic kinematic formulas for determining phase times (McGee et al., 2012). Exploration of the increased use of these formulas is recommended for mitigating the significant variability of reaction times between drivers.

Verbal interfaces, such as Siri, Google Assistant, and Amazon Alexa, are increasingly embedded in phones and vehicles. Verbal interfaces offer a way of reducing button pressing while driving (Greengard, 2015). As is evident in our study, verbal responses conferred a performance advantage, as they were faster than foot pedal responses (Table 1, Fig. 4a) and facilitated more accurate classifications in the dual task (Fig. 5d). Verbal interfaces might mitigate the negative effects of multitasking and increase driving efficiency. Tentative evidence that vehicle speech interfaces can lead to more consistent driving (Barón \& Green, 2006) complements these findings. However, Strayer, Turrill, Coleman, Ortiz, and Cooper (2014) and Cooper, Ingebretsen, and Strayer (2014) noted that verbal interfaces can create high cognitive demand for drivers, due to imperfect reliability and driver inexperience with the technology; however, verbal interfaces are constantly improving. Further research will be needed to confirm the effectiveness of verbal interface systems for reducing driver 
distraction and facilitating higher response speeds and consistency while driving.

\section{Closing remarks}

In conclusion, this study demonstrates that multitasking prolongs reaction times to yellow traffic lights and that explicit verbal responses are faster than implicit foot pedal responses. The primary implication of this study is that multitasking can increase risk for drivers navigating intersections, with performance decline resulting from lower levels of additional cognitive load than could be undertaken during real-world multitasking. The performance increases observed for explicit responses require further observation. More sensitive measures will be required to ascertain the effects of topdown motivations on yellow traffic light responses. Recommendations for public policy include (1) adopting dynamic equations for determining yellow traffic light durations, (2) restrictions against multitasking that take into account the cognitive impairment of multitasking, (3) investment in research into the viability of in-vehicle ICWSs, and (4) investment to promote improvement in voice-command car systems.

Author note The authors thank the School of Psychology and Public Health at La Trobe University and the Australian Research Council (DP170103189) for providing financial support for this study. The data reported in this article are available upon request. None of the experiments were preregistered.

\section{Appendix 1: Driver background questionnaire}

1. Approximately how many years driving experience do you have?

2. Approximately how many hours would you regularly spend driving per week?

3. Have you experienced a vehicle accident in the last 6 months that has made you more cautious or less confident while driving? Y/N

4. Have you experienced a "near miss" in the last 6 months that has made you more cautious or less confident while driving? Y/N

5. Have you had a driving offence detected by police or automated cameras in the last 6 months. Y/N
Appendix 2: Dual-task word lists

Table 3 Word lists for animal-artefact identification task

\begin{tabular}{|c|c|c|c|}
\hline List 1 & List 2 & List 3 & List 4 \\
\hline Bed & Book & Chair & Door \\
\hline Finger & Hand & Nose & Table \\
\hline Toe & Glass & House & Key \\
\hline Leg & Lips & Pants & Pen \\
\hline Sweater & Bread & Ear & Eye \\
\hline Foot & Lamp & Pencil & Shoe \\
\hline Socks & Tree & Watch & Arm \\
\hline Bottle & Cup & Sun & Thumb \\
\hline Car & Glasses & Ruler & Apple \\
\hline Pot & Shirt & Belt & Cigarette \\
\hline Coat & Leaf & Scissors & Flower \\
\hline Frying Pan & Hanger & Knife & Orange \\
\hline Tomato & Truck & Banana & Blouse \\
\hline Dog & Cat & Bird & Cow \\
\hline Chicken & Horse & Rabbit & Duck \\
\hline Fly & Butterfly & Rooster & Fish \\
\hline Ant & Mouse & Snail & Sheep \\
\hline Bee & Donkey & Pig & Squirrel \\
\hline Goat & Frog & Turtle & Swan \\
\hline Owl & Fox & Caterpillar & Deer \\
\hline Monkey & Lion & Eagle & Lobster \\
\hline Elephant & Peacock & Bear & Camel \\
\hline Penguin & Gorilla & Zebra & Giraffe \\
\hline Raccoon & Snake & Alligator & Ostrich \\
\hline Sea Horse & Skunk & Tiger & Seal \\
\hline
\end{tabular}

The words in Word Lists 1 and 2 were reversed for use in the single-task condition.

\section{Appendix 3}

Table 4 Mean familiarity scores for word lists in the animal-artefact identification task $(n=25)$

\begin{tabular}{lll}
\hline Condition & $M$ & $S D$ \\
\hline List 1 & 3.81 & 1.26 \\
List 2 & 3.85 & 1.19 \\
List 3 & 3.83 & 1.20 \\
List 4 & 3.78 & 1.21 \\
\hline
\end{tabular}




\section{Appendix 4}

Table 5 Times and distances from the intersection when yellow traffic light onsets occur during the simulated intersection approach

\begin{tabular}{|c|c|c|c|c|c|c|c|c|c|c|}
\hline \multirow[t]{2}{*}{ Measure } & \multicolumn{10}{|c|}{ Timing } \\
\hline & 1 & 2 & 3 & 4 & 5 & 6 & 7 & 8 & 9 & 10 \\
\hline Time from the intersection (s) & 1.3 & 1.7 & 2.0 & 2.4 & 2.7 & 3.1 & 3.4 & 3.8 & 4.1 & 4.5 \\
\hline Distance from the intersection (m) & 21.7 & 27.6 & 33.5 & 39.4 & 45.4 & 51.3 & 57.2 & 63.1 & 69.1 & 75.0 \\
\hline
\end{tabular}

\section{References}

AA Insurance. (2014). TXTing, reading, and attractive pedestrians all distracting for drivers [Press release]. Retrieved from www. aainsurance.co.nz

Adobe Systems. (2015). Adobe Photoshop CC [Computer software]. San Jose, CA: Adobe Systems.

Australian Mobile Telecommunications Association. (2015). AMTA dial up campaign to promote safe and responsible phone use while driving [Press release]. Retrieved from www.amta.org.au

Bartlett, M. S., Littlewort, G., Vural, E., Lee, K., Cetin, M., \& Ercil, A. (2007). Data Mining Spontaneous Facial Behavior with Automatic Expression Coding. In A. Esposito, N. Bourbakis, N. Avouris, \& I. Hatzilygeroudis (Eds.), Verbal and Nonverbal Features of HumanHuman and Human-Machine Interaction (Vol. 5042, pp. 1-21). Verlag: Springer.

Ball, K., Owsley, C., Stalvey, B., Roenker, D. L., Sloane, M. E., \& Graves, M. (1998). Driving avoidance and functional impairment in older drivers. Accident Analysis and Prevention, 30, 313-322. https://doi.org/10.1016/S0001-4575(97)00102-4

Barón, A., \& Green, P. (2006). Safety and usability of speech interfaces for in-vehicle tasks while driving: A brief literature review. Ann Arbor, MI: University of Michigan, Transportation Research Institute. Retrieved from http://umich.edu/ driving/publications/ UMTRI-2006-5a.pdf

Belz, S. M., Robinson, G. S., \& Casali, J. G. (1999). A new class of auditory warning signals for complex systems: Auditory icons. Human Factors, 41, 608-618. https://doi.org/10.1518/ 001872099779656734

Blaser, E., \& Shepard, T. (2009). Maximal motion aftereffects in spite of diverted awareness. Vision Research, 49, 1174-1181. https://doi. org/10.1016/j.visres.2008.09.012

Bonneson, J. A., Middleton, D., \& Zimmerman, K. (2002). Intelligent detection-control system for rural signalized intersections. (FHWA/TX-02/4022-2). Austin, TX: Texas Department of Transportation. Retrieved from http://trid.trb.org/view.aspx?id=731149

Breakwell, G. M. (2006). Research methods in psychology. London, UK: Sage.

Brookhuis, K., Waard, D. D., \& Mulder, B. (1994). Measuring driving performance by car-following in traffic. Ergonomics, 37, 427-434. https://doi.org/10.1080/00140139408963661

Bureau of Infrastructure Transport and Regional Economics. (2013). Road deaths Australia: 2012 statistical summary. Retrieved from Canberra: https://bitre.gov.au/publications/ongoing/files/RDA_ Summary_2012_June.pdf

Caird, J. K., Edwards, C. J., Creaser, J. I., \& Horrey, W. J. (2005). Older driver failures of attention at intersections: Using change blindness methods to assess turn decision accuracy. Human Factors, 47, 235 249. https://doi.org/10.1518/0018720054679542
Caird, J. K., Johnston, K. A., Willness, C. R., Asbridge, M., \& Steel, P. (2014). A meta-analysis of the effects of texting on driving. Accident Analysis and Prevention, 71, 311-318. https://doi.org/10.1016/j.aap. 2014.06.005

Caird, J. K., Willness, C. R., Steel, P., \& Scialfa, C. (2008). A metaanalysis of the effects of cell phones on driver performance. Accident Analysis and Prevention, 40, 1282-1293. https://doi.org/ 10.1016/j.aap.2008.01.009

Campagne, A., Pebayle, T., \& Muzet, A. (2004). Correlation between driving errors and vigilance level: Influence of the driver's age. Physiology and Behavior, 80, 515-524. https://doi.org/10.1016/j. physbeh.2003.10.004

Carney, C., McGehee, D., Harland, K., Weiss, M., \& Raby, M. (2015). Using naturalistic driving data to assess the prevalence of environmental factors and driver behaviors in teen driver crashes. Washington, DC: AAA Foundation for Traffic Safety. Retrieved from www.aaafoundation.org

Carrasco, M., \& McElree, B. (2001). Covert attention accelerates the rate of visual information processing. Proceedings of the National Academy of Sciences, 98, 5363-5367. https://doi.org/10.1073/ pnas.081074098

Carrasco, M., Penpeci-Talgar, C., \& Eckstein, M. (2000). Spatial covert attention increases contrast sensitivity across the CSF: Support for signal enhancement. Vision Research, 40, 1203-1215. https://doi. org/10.1016/S0042-6989(00)00024-9

Castiello, U., \& Jeannerod, M. (1991). Measuring time to awareness. NeuroReport, 2, 797-800. https://doi.org/10.1097/00001756199112000-00017

Castiello, U., Paulignan, Y., \& Jeannerod, M. (1991). Temporal dissociation of motor responses and subjective awareness: A study in normal subjects. Brain, 114, 2639-2655. https://doi.org/10.1093/brain/ 114.6.2639

Cerezuela, G. P., Tejero, P., Chóliz, M., Chisvert, M., \& Monteagudo, M. J. (2004). Wertheim's hypothesis on "highway hypnosis": Empirical evidence from a study on motorway and conventional road driving. Accident Analysis and Prevention, 36, 1045-1054. https://doi.org/ 10.1016/j.aap.2004.02.002

Chang, S.-H., Lin, C.-Y., Hsu, C.-C., Fung, C.-P., \& Hwang, J.-R. (2009). The effect of a collision warning system on the driving performance of young drivers at intersections. Transportation Research Part F: Traffic Psychology and Behaviour, 12, 371-380. https://doi.org/10. 1016/j.trf.2009.05.001

Chapman, P., Ismail, R., \& Underwood, G. J. (1999). Waking up at the wheel: Accidents, attention and the time-gap experience. In A. G. Gale, I. D. Brown, C. M. Haslegrave, \& S. P. Taylor (Eds.), Vision in vehicles (Vol. 7, pp. 131-138). Amsterdam, The Netherlands: Elsevier.

Chen, H., Cao, L., \& Logan, D. B. (2011). Investigation into the effect of an intersection crash warning system on driving performance in a simulator. Traffic Injury Prevention, 12, 529-537. https://doi.org/10. 1080/15389588.2011.603169 
Cisek, P., \& Kalaska, J. F. (2005). Neural correlates of reaching decisions in dorsal premotor cortex: Specification of multiple direction choices and final selection of action. Neuron, 45, 801-814. https:// doi.org/10.1016/j.neuron.2005.01.027

Cooper, J. M., Ingebretsen, H., \& Strayer, D. (2014). Measuring cognitive distraction in the automobile: IIa. Mental demands of voice-based vehicle interactions with OEM system. Washington, DC: AAA Foundation for Traffic Safety. Retrieved from www.aaafoundation.org

Coutts, E., \& Jann, B. (2011). Sensitive questions in online surveys: Experimental results for the Randomized Response Technique (RRT) and the Unmatched Count Technique (UCT). Sociological Methods \& Research, 40, 169-193. https://doi.org/10.1177/ 0049124110390768

David, R. (2015, September 11). More than 50,000 fines issued at four speed camera sites in three months. Herald Sun. Retrieved from http://www.heraldsun.com.au/

Dux, P. E., Ivanoff, J., Asplund, C. L., \& Marois, R. (2006). Isolation of a central bottleneck of information processing with time-resolved FMRI. Neuron, 52, 1109-1120. https://doi.org/10.1016/j.neuron. 2006.11.009

Elmitiny, N., Yan, X., Radwan, E., Russo, C., \& Nashar, D. (2010). Classification analysis of driver's stop/go decision and red-light running violation. Accident Analysis and Prevention, 42, 101-111. https://doi.org/10.1016/j.aap.2009.07.007

Etienne, V., Marin-Lamellet, C., \& Laurent, B. (2013). Mental flexibility impairment in drivers with early Alzheimer's disease: A simulatorbased study. International Association of Traffic and Safety Sciences Research, 37, 16-20. https://doi.org/10.1016/j.iatssr.2013.06.005

Evans, J. S. (2008). Dual-processing accounts of reasoning, judgment, and social cognition. Annual Review of Psychology, 59, 255-278. https://doi.org/10.1146/annurev.psych.59.103006.093629

Ferguson, M. J., \& Bargh, J. A. (2004). How social perception can automatically influence behavior. Trends in Cognitive Sciences, 8, 33 39. https://doi.org/10.1016/j.tics.2003.11.004

Glass, A., Cox, J., \& LeVine, S. (1974). Distinguishing familiarity from list search responses in a reaction time task. Bulletin of the Psychonomic Society, 4, 105-108. https://doi.org/10.3758/ BF03334211

Goddard, T., Kahn, K. B., \& Adkins, A. (2015). Racial bias in driver yielding behavior at crosswalks. Transportation Research Part F: Traffic Psychology and Behaviour, 33, 1-6. https://doi.org/10.1016/ j.trf.2015.06.002

Goh, P.-K., \& Wong, Y.-D. (2004). Driver perception response time during the signal change interval. Applied Health Economics and Health Policy, 3, 9-15. https://doi.org/10.2165/00148365200403010-00004

Gracco, V. L., \& Abbs, J. H. (1987). Programming and execution processes of speech movement control: Potential neural correlates. In E. Keller \& M. Gopnik (Eds.), Motor and sensory processes of language (pp. 163-201). Hillsdale, NJ: Erlbaum.

Gras, M. E., Sullman, M. J. M., Cunill, M., Planes, M., Aymerich, M., \& Font-Mayolas, S. (2006). Spanish drivers and their aberrant driving behaviours. Transportation Research Part F: Traffic Psychology and Behaviour, 9, 129-137. https://doi.org/10.1016/j.trf.2005.09.004

Greengard, S. (2015). Automotive systems get smarter. Communications of the ACM, 58, 18-20. https://doi.org/10.1145/2811286

Groeger, J. A., \& Brown, I. D. (1989). Assessing one's own and others' driving ability: Influences of sex, age, and experience. Accident Analysis and Prevention, 21, 155-168. https://doi.org/10.1016/ 0001-4575(89)90083-3

Gugerty, L., McIntyre, S. E., Link, D., Zimmerman, K., Tolani, D., Huang, P., \& Pokorny, R. A. (2014). Effects of intelligent advanced warnings on drivers negotiating the dilemma zone. Human Factors, 56, 1021-1035. https://doi.org/10.1177/0018720814525438

Hancock, P. A., Lesch, M., \& Simmons, L. (2003). The distraction effects of phone use during a crucial driving maneuver. Accident Analysis and Prevention, 35, 501-514. https://doi.org/10.1016/S00014575(02)00028-3

Harbluk, J. L., Noy, Y. I., Trbovich, P. L., \& Eizenman, M. (2007). An onroad assessment of cognitive distraction: Impacts on drivers' visual behavior and braking performance. Accident Analysis and Prevention, 39, 372-379. https://doi.org/10.1016/j.aap.2006.08.013

Hatfield, J., \& Job, R. F. (2006). Beliefs and attitudes about speeding and its countermeasures (B2001/0342). Sydney, Australia: University of Sydney.

Hazeltine, E., Ruthruff, E., \& Remington, R. W. (2006). The role of input and output modality pairings in dual-task performance: Evidence for content-dependent central interference. Cognitive Psychology, 52, 291-345. https://doi.org/10.1016/j.cogpsych.2005.11.001

Hurwitz, D. S., Miller, E., Jannat, M., Boyle, L. N., Brown, S., AbdelRahim, A., \& Wang, H. (2016). Improving teenage driver perceptions regarding the impact of distracted driving in the pacific northwest. Journal of Transportation Safety and Security, 8, 148-163. https://doi.org/10.1080/19439962.2014.997329

Irwin, C., Monement, S., \& Desbrow, B. (2014). The influence of drinking, texting, and eating on simulated driving performance. Traffic Injury Prevention, 16, 116-123. https://doi.org/10.1080/15389588. 2014.920953

Jensen, C. (2011, May 26). What to do at a yellow light? And other things American drivers don't know. New York Times. Retrieved from www.nytimes.com

Just, M. A., Keller, T. A., \& Cynkar, J. (2008). A decrease in brain activation associated with driving when listening to someone speak. Brain Research, 1205, 70-80. https://doi.org/10.1016/j.brainres. 2007.12.075

Kidd, D. G., Tison, J., Chaudhary, N. K., McCartt, A. T., \& CasanovaPowell, T. D. (2016). The influence of roadway situation, other contextual factors, and driver characteristics on the prevalence of driver secondary behaviors. Transportation Research Part F: Traffic Psychology and Behaviour, 41, 1-9. https://doi.org/10. 1016/j.trf.2016.06.004

Knowles, D., \& Tay, R. (2002). Driver inattention: More risky than the fatal four? Proceedings of the Australasian Road Safety Research, Policing and Education Conference, 6, 107-111. http://eprints.qut. edu.au/5577

Koch, C., \& Tsuchiya, N. (2007). Attention and consciousness: Two distinct brain processes. Trends in Cognitive Sciences, 11, 16-22. https://doi.org/10.1016/j.tics.2006.10.012

Korner-Bitensky, N., Kua, A., von Zweck, C., \& Van Benthem, K. (2009). Older driver retraining: An updated systematic review of evidence of effectiveness. Journal of Safety Research, 40, 105111. https://doi.org/10.1016/j.jsr.2009.02.002

Kruglanski, A. W., \& Webster, D. M. (1996). Motivated closing of the mind: "Seizing" and "freezing." Psychological Review, 103, 263283.

Lajunen, T., Corry, A., Summala, H., \& Hartley, L. (1997). Impression management and self-deception in traffic behaviour inventories. Personality and Individual Differences, 22, 341-353. https://doi. org/10.1016/S0191-8869(96)00221-8

Lajunen, T., \& Summala, H. (2003). Can we trust self-reports of driving? Effects of impression management on driver behaviour questionnaire responses. Transportation Research Part F: Traffic Psychology and Behaviour, 6, 97-107. https://doi.org/10.1016/ S1369-8478(03)00008-1

Langford, J., Methorst, R., \& Hakamies-Blomqvist, L. (2006). Older drivers do not have a high crash risk: A replication of low mileage bias. Accident Analysis and Prevention, 38, 574-578. https://doi. org/10.1016/j.aap.2005.12.002

Lee, J., Forlizzi, J., Hudson, S. E., \& Jun, S. (2014). Use of the backseat driving technique in evaluation of a perceptually optimized in-car navigation display. International Journal of Human Computer 
Interaction, 31, 128-138. https://doi.org/10.1080/10447318.2014. 959104

Legge, G. E., \& Campbell, F. W. (1981). Displacement detection in human vision. Vision Research, 21, 205-213. https://doi.org/10.1016/ 0042-6989(81)90114-0

Levasseur, M., \& Akcelik, R. (2014). Guide to traffic management part 9: Traffic operations (2nd ed.). Sydney, Australia: Austroads.

Li, X., Liang, Z., Kleiner, M., \& Lu, Z.-L. (2010). RTbox: A device for highly accurate response time measurements. Behavior Research Methods, 42, 212-225. https://doi.org/10.3758/BRM.42.1.212

Lisper, H. O., Laurell, H., \& Van Loon, J. (1986). Relation between time to falling asleep behind the wheel on a closed track and changes in subsidiary reaction time during prolonged driving on a motorway. Ergonomics, 29, 445-453. https://doi.org/10.1080/ 00140138608968278

Logan, G. D. (1979). On the use of a concurrent memory load to measure attention and automaticity. Journal of Experimental Psychology: Human Perception and Performance, 5, 189-207. https://doi.org/ 10.1037/0096-1523.5.2.189

Lu, Z. L., \& Dosher, B. A. (1998). External noise distinguishes attention mechanisms. Vision Research, 38, 1183-1198. http:/www.ncbi. nlm.nih.gov/pubmed/9666987

Luck, S. J. (1998). Sources of dual-task interference: Evidence from human electrophysiology. Psychological Science, 9, 223-227. https://doi.org/10.1111/1467-9280.00043

Lupyan, G., \& Ward, E. J. (2013). Language can boost otherwise unseen objects into visual awareness. Proceedings of the National Academy of Sciences, 110, 14196-14201. https://doi.org/10.1073/pnas. 1303312110

Lynn, S. K., \& Barrett, L. F. (2014). "Utilizing” signal detection theory. Psychological Science, 25, 1663-1673. https://doi.org/10.1177/ 0956797614541991

Ma, H.-I., Hwang, W.-J., \& Lin, K.-C. (2009). The effects of two different auditory stimuli on functional arm movement in persons with Parkinson's disease: A dual-task paradigm. Clinical Rehabilitation, 23, 229-237. https://doi.org/10.1177/0269215508098896

Marottoli, R. A., \& Richardson, E. D. (1998). Confidence in, and selfrating of, driving ability among older drivers. Accident Analysis and Prevention, 30, 331-336. https://doi.org/10.1016/S0001-4575(97) 00100-0

Marusek, S. (2014). Visual jurisprudence of the American yellow traffic light. International Journal for the Semiotics of Law, 27, 183-191. https://doi.org/10.1007/s11196-013-9323-Z

McCartt, A. T., Shabanova, V. I., \& Leaf, W. A. (2003). Driving experience, crashes and traffic citations of teenage beginning drivers. Accident Analysis and Prevention, 35, 311-320. https://doi.org/10. 1016/S0001-4575(02)00006-4

McGee, H., Moriarty, K., Eccles, K., Liu, M., Gates, T., \& Retting, R. (2012). Guidelines for timing yellow and all-red intervalsat signalized intersections. Washington, DC: Transportation Research Board Retrieved from http://onlinepubs.trb.org/onlinepubs/nchrp/nchrp rpt_731.pdf

McGwin, G., Chapman, V., \& Owsley, C. (2000). Visual risk factors for driving difficulty among older drivers. Accident Analysis and Prevention, 32, 735-744. https://doi.org/10.1016/S0001-4575(99) 00123-2

Møller, M., \& Gregersen, N. P. (2008). Psychosocial function of driving as predictor of risk-taking behaviour. Accident Analysis and Prevention, 40, 209-215. https://doi.org/10.1016/j.aap.2007.05.007

Montag, E. D., \& Wilber, D. C. (2003). A comparison of constant stimuli and gray-scale methods of color difference scaling. Color Research and Application, 28, 36-44. https://doi.org/10.1002/col.10112

Motulsky, H. J. (2014). Common misconceptions about data analysis and statistics. Naunyn-Schmiedeberg's Archives of Pharmacology, 387, 1017-1023. https://doi.org/10.1007/s00210-014-1037-6
Nyberg, L., Petersson, K. M., Nilsson, L.-G., Sandblom, J., Åberg, C., \& Ingvar, M. (2001). Reactivation of motor brain areas during explicit memory for actions. NeuroImage, 14, 521-528. https://doi.org/10. 1006/nimg.2001.0801

Owsley, C., Ball, K., McGwin, G., Jr., Sloane, M. E., Roenker, D. L., White, M. F., \& Overley, E. T. (1998). Visual processing impairment and risk of motor vehicle crash among older adults. Journal of the American Medical Association, 279, 1083-1088. https://doi.org/10. 1001/jama.279.14.1083.

Pashler, H. (1994). Dual-task interference in simple tasks: Data and theory. Psychological Bulletin, 116, 220-244. https://doi.org/10.1037/ 0033-2909.116.2.220

Pelli, D. G., \& Bex, P. (2013). Measuring contrast sensitivity. Vision Research, 90, 10-14. https://doi.org/10.1016/j.visres.2013.04.015

Perugini, M., Conner, M., \& O'Gorman, R. (2011). Automatic activation of individual differences: A test of the gatekeeper model in the domain of spontaneous helping. European Journal of Personality, 25, 465-476. https://doi.org/10.1002/per.826

Plant, R. R., Hammond, N., \& Turner, G. (2004). Self-validating presentation and response timing in cognitive paradigms: How and why? Behavior Research Methods, Instruments, \& Computers, 36, 291303. http://link.springer.com/article/10.3758\%2FBF03195575

Plant, R. R., Hammond, N., \& Whitehouse, T. (2003). How choice of mouse may affect response timing in psychological studies. Behavior Research Methods, Instruments, \& Computers, 35, 276 284. https://doi.org/10.3758/BF03202553

Plant, R. R., \& Turner, G. (2009). Millisecond precision psychological research in a world of commodity computers: New hardware, new problems? Behavior Research Methods, 41, 598-614. https://doi. org/10.3758/BRM.41.3.598

Psychology Software Tools Inc. (2012). E-Prime 2.0. Retrieved from http://www.pstnet.com

Rakha, H., El-Shawarby, I., \& Setti, J. R. (2007). Characterizing driver behavior on signalized intersection approaches at the onset of a yellow-phase trigger. Intelligent Transportation Systems, 8, 630640. https://doi.org/10.1109/TITS.2007.908146

Ratcliff, R. (1993). Methods for dealing with reaction time outliers. Psychological Bulletin, 114, 510-532. https://doi.org/10.1037/ 0033-2909.114.3.510

Redelmeier, D. A., \& Tibshirani, R. J. (1997). Association between cellular-telephone calls and motor vehicle collisions. New England Journal of Medicine, 336, 453-458. https://doi.org/10.1056/ NEJM199702133360701

Rossion, B., \& Pourtois, G. (2004). Revisiting Snodgrass and Vanderwart's object pictorial set: The role of surface detail in basic-level object recognition. Perception, 33, 217-236. https:// doi.org/10.1068/p5117

Rothengatter, T. (1982). The effects of police surveillance and law enforcement on driver behaviour. Current Psychological Reviews, 2, 349-358. https://doi.org/10.1007/BF02684467

Rubinstein, J. S., Meyer, D. E., \& Evans, J. E. (2001). Executive control of cognitive processes in task switching. Journal of Experimental Psychology: Human Perception and Performance, 27, 763-797.

Sagberg, F., \& Bjornskau, T. (2006). Hazard perception and driving experience among novice drivers. Accident Analysis and Prevention, 38, 407-414. https://doi.org/10.1016/j.aap.2005.10.014

Salvucci, D. D., \& Taatgen, N. A. (2008). Threaded cognition: An integrated theory of concurrent multitasking. Psychological Review, 115, 101-130. https://doi.org/10.1037/0033-295X.115.1.101

Saults, J. S., \& Cowan, N. (2007). A central capacity limit to the simultaneous storage of visual and auditory arrays in working memory. Journal of Experimental Psychology: General, 136, 663-684. https://doi.org/10.1037/0096-3445.136.4.663

Schall, J. D. (2009). Executive function and higher-order cognition: Assessment in animals. In M. Binder (Ed.), Encyclopedia of neuroscience (Vol. 4, pp. 87-92.). Berlin, Germany: Springer. 
Scheel, M. H. (2010). Resource depletion promotes automatic processing: Implications for distribution of practice. Psychological Reports, 107, 860-872. https://doi.org/10.2466/04.22.PR0.107.6.860-872

Schneider, W., \& Chein, J. M. (2003). Controlled and automatic processing: Behavior, theory, and biological mechanisms. Cognitive Science, 27, 525-559. https://doi.org/10.1016/S0364-0213(03) $00011-9$

Schumacher, E. H., Seymour, T. L., Glass, J. M., Fencsik, D. E., Lauber, E. J., Kieras, D. E., \& Meyer, D. E. (2001). Virtually perfect time sharing in dual-task performance: Uncorking the central cognitive bottleneck. Psychological Science, 12, 101-108.

Shamoa-Nir, L., \& Koslowsky, M. (2010). Aggression on the road as a function of stress, coping strategies and driver style. Psychology, 1, 35-44. https://doi.org/10.4236/psych.2010.11006.

Shine, J. M., \& Shine, R. (2014). Delegation to automaticity: The driving force for cognitive evolution? Frontiers in Neuroscience, 8, 90. https://doi.org/10.3389/fnins.2014.00090

Smith, S. M. (1995). Getting into and out of mental ruts: A theory of fixation, incubation, and insight. In R. J. S. J. E. Davidson (Ed.), The nature of insight (pp. 229-251). Cambridge, MA, US: MIT Press.

Snodgrass, J. G., \& Vanderwart, M. (1980). A standardized set of 260 pictures: Norms for name agreement, image agreement, familiarity, and visual complexity. Journal of Experimental Psychology: Human Learning and Memory, 6, 174-215. https://doi.org/10. 1037/0278-7393.6.2.174

Stanislaw, H., \& Todorov, N. (1999). Calculation of signal detection theory measures. Behavior Research Methods, Instruments, \& Computers, 31, 137-149. https://doi.org/10.3758/BF03207704

Stanley, J., \& Krakauer, J. W. (2013). Motor skill depends on knowledge of facts. Frontiers in Human Neuroscience, 7, 503. https://doi.org/ 10.3389/fnhum.2013.00503

Stein, A. C., \& Dubinsky, R. M. (2011). Driving simulator performance in patients with possible and probable Alzheimer's disease. Annals of Advances in Automotive Medicine, 55, 325-334.

Stein, H. S. (1986). Traffic signal change intervals: Policies, practices, and safety. Transportation Quarterly, 40, 433-445

Steinberg, L. (2007). Risk taking in adolescence: New perspectives from brain and behavioral science. Current Directions in Psychological Science, 16, 55-59. https://doi.org/10.1111/j.1467-8721.2007.00475.x

Stokes, D. (2013). Cognitive penetrability of perception. Philosophy Compass, 8, 646-663. https://doi.org/10.1111/phc3.12043

Strayer, D. L., Drews, F. A., \& Crouch, D. J. (2006). A comparison of the cell phone driver and the drunk driver. Human Factors, 48, 381391. https://doi.org/10.1518/001872006777724471

Strayer, D. L., Turrill, J., Coleman, J., Ortiz, E., \& Cooper, J. M. (2014). Measuring cognitive distraction in the automobile: II. Assessing invehicle voice-based interactive technologies. Washington, DC: AAA Foundation for Traffic Safety. Retrieved from www. aaafoundation.org

Strayer, D. L., Watson, J. M., \& Drews, F. A. (2011). Cognitive distraction while multitasking in the automobile. In B. H. Ross (Ed.), The psychology of learning and motivation (Vol. 54, pp. 29-58). Burlington, MA: Academic Press.

Struthers, D. (2015, 20 March 2015). 5628-E-Prime 2.0 timing data. Retrieved from https://support.pstnet.com/entries/90992687

Stutts, J. C., Stewart, J. R., \& Martell, C. (1998). Cognitive test performance and crash risk in an older driver population. Accident Analysis and Prevention, 30, 337-346. https://doi.org/10.1016/ S0001-4575(97)00108-5

Sullman, M. J. M., \& Taylor, J. E. (2010). Social desirability and selfreported driving behaviours: Should we be worried? Transportation Research Part F: Traffic Psychology and Behaviour, 13, 215-221. https://doi.org/10.1016/j.trf.2010.04.004

Taubman Ben-Ari, O., Florian, V., \& Mikulincer, M. (2000). Does a threat appeal moderate reckless driving? A terror management theory perspective. Accident Analysis and Prevention, 32, 1-10. https:// doi.org/10.1016/S0001-4575(99)00042-1

Templeton, R. K., \& Franklin, J. (1992). Adaptive information and animal behaviour: Why motorists stop at red traffic lights. Evolutionary Theory, 10, 145-155. http://web.maths.unsw.edu.au/ jim/ templeton.pdf

Urban, F. M. (1910). The method of constant stimuli and its generalizations. Psychological Review, 17, 229. https://doi.org/10.1037/ h0074515

Valdesolo, P., \& DeSteno, D. (2008). The duality of virtue: Deconstructing the moral hypocrite. Journal of Experimental Social Psychology, 44, 1334-1338. https://doi.org/10.1016/j.jesp. 2008.03.010

van Baaren, R. B., Holland, R. W., Kawakami, K., \& van Knippenberg, A. (2004). Mimicry and prosocial behavior. Psychological Science, 15, 71-74. https://doi.org/10.1111/j.0963-7214.2004.01501012.x

Victorian Government. (2009). Road safety road rules. http://www. legislation.vic.gov.au/

Vural, E., Cetin, M., Ercil, A., Littlewort, G., Bartlett, M., \& Movellan, J. (2009). Machine learning systems for detecting driver drowsiness. In K. Takeda, H. Erdogan, J. L. Hansen, \& H. Abut (Eds.), InVehicle Corpus and Signal Processing for Driver Behavior (pp. 97-110). New York: Springer.

Welford, A. T. (1952). The "psychological refractory period" and the timing of high-speed performance: A critical review and a theory. British Journal of Psychology. General Section, 43, 2-19. https:// doi.org/10.1111/j.2044-8295.1952.tb00322.x

West, R., French, D., Kemp, R., \& Elander, J. (1993). Direct observation of driving, self reports of driver behaviour, and accident involvement. Ergonomics, 36, 557-567. https://doi.org/10.1080/ 00140139308967912

Wickens, C. D., \& McCarley, J. S. (2008). Applied attention theory. Boca Raton, FL: CRC Press.

Wilson, T. D., Lindsey, S., \& Schooler, T. Y. (2000). A model of dual attitudes. Psychological Review, 107, 101-126. https://oi.org/10. 1037/0033-295X.107.1.101

Wishart, D. E., Freeman, J. E., \& Davey, J. D. (2006). Utilising the Driver Behaviour Questionnaire in an organisational fleet setting. Journal of the Australasian College of Road Safety, 17, 31-38. https:// eprints.qut.edu.au/5956

Wood, D. K., Chouinard, P. A., Major, A. J., \& Goodale, M. A. (2017). Sensitivity to biomechanical limitations during postural decisionmaking depends on the integrity of posterior superior parietal cortex. Cortex, 97, 202-220. https://doi.org/10.1016/j.cortex.2016.07.005

Xue, G., Aron, A. R., \& Poldrack, R. A. (2008). Common neural substrates for inhibition of spoken and manual responses. Cerebral Cortex, 18, 1923-1932. https://doi.org/10.1093/cercor/bhm220

Yan, X., Xue, Q., Ma, L., \& Xu, Y. (2014). Driving-simulator-based test on the effectiveness of auditory red-light running vehicle warning system based on time-to-collision sensor. Sensors, 14, 3631-3651. https://doi.org/10.3390/s140203631

Yeshurun, Y., \& Carrasco, M. (1999). Spatial attention improves performance in spatial resolution tasks. Vision Research, 39, 293-306. https://doi.org/10.1016/S0042-6989(98)00114-X

Zhang, Y., Fu, C., \& Hu, L. (2014). Yellow light dilemma zone researches: A review. Journal of Traffic and Transportation Engineering, 1, 338-352. https://doi.org/10.1016/S2095-7564(15)30280-4

Publisher's note Springer Nature remains neutral with regard to jurisdictional claims in published maps and institutional affiliations. 